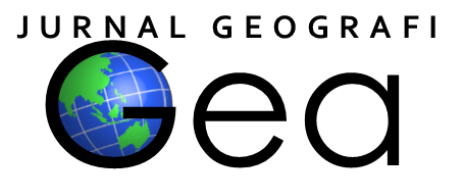

\title{
ANALISIS RISIKO BANJIR TERHADAP FASILITAS PENDIDIKAN DI DKI JAKARTA
}

\author{
Siti Dahlia ${ }^{1}$, Fadiarman ${ }^{2}$ \\ ${ }^{1,2}$ Pendidikan Geografi, FKIP UHAMKA, Jakarta Indonesia \\ sitidahlia@uhamka.ac.id, 20 fadiarman1963@gmail.com
}

\begin{abstract}
Jakarta Province as the capital city of the country, has a strategic function, namely as a center for economic and business growth, a government center, and an education center. However, Jakarta is prone area to flooding which impacts on various elements at risik, one of that is schools. The impact of flooding on the school environment has the potential to obstruct the learning process, losses, damage, and fatalities. Flood mitigation efforts are important to reduce the level of risk of loss, damage and fatalities. Based on this, the research objectives are: 1). To map the flood hazard level; 2). To assess the level of school vulnerability to flooding; 3). Flood risk analysis of educational facilities especially High Schools. The research method used to create map of floods hazard was spatial analysis based on elevation data, landforms, land use, and historical flood events. Vulnerability assessment method used weighting and scoring system on each parameter with a scale of 0-1. Risk analysis used qualitative analysis using risk matrices. The results of the analysis that areas with low flood hazard levels is 13,613.40 ha, medium flood hazard levels is 23,238.67 ha, and high flood hazard levels of 27,216.72 ha. Based on the school vulnerability assessment of flooding shows that there are 8 non-vulnerable schools, 22 with low vulnerability schools, 16 medium vulnerability schools, and 4 high vulnerability schools. Based on an analysis of school risks to flooding, there are 10 low risk schools, 27 moderate risk schools, and 13 high risk schools. The analysis results were identified as being consistent between the highest areas of vulnerability and risk, namely the North and West Jakarta areas.
\end{abstract}

Keywords: Hazard, Vulnerability, Flood Risk Analysis, School

\begin{abstract}
ABSTRAK
Provinsi DKI Jakarta sebagai Ibu Kota negara, memiliki fungsi startegis yaitu sebagai pusat pertumbuhan ekonomi dan bisnis, pusat pemerintahan, dan pusat pendidikan. Akan tetapi, DKI Jakarta merupakan area yang rawan terhadap bencana banjir, yang berdampak pada berbagai elemen berisiko salah satunya yaitu sekolah. Dampak terjadi banjir pada lingkungan sekolah berpotensi menghambat proses pembelajaran, kerugian, kerusakan, bahkan korban jiwa. Upaya penanggulangan banjir merupakan penting sebagai upaya penurunan tingkat risiko kerugian, kerusakan, dan korban jiwa. Berdasarkan hal tersebut, tujuan penelitian yaitu: 1). Untuk memetakan tingkat bahaya banjir DKI Jakarta; 2). Menilai tingkat kerentanan sekolah terhadap banjir; 3). Analisis risiko banjir terhadap fasilitas pendidikan khususnya Sekolah Menengah Atas di DKI Jakarta. Metode penelitian yang digunakan yaitu untuk memetakan banjir yaitu analisis
\end{abstract}


spasial berdasarkan data elevasi, bentuklahan, penggunaan lahan, dan historis kejadian banjir. Metode penilaian kerentanan menggunakan system pembobotan dan skoring pada setiap parameter dengan skala 0-1. Analsisi risiko menggunakan analisis secara kualitatif menggunakan matrkis risiko. Hasil analisis yaitu daerah dengan tingkat kerawanan banjir rendah seluas 13.613,40 ha, sedang seluas 23.238,67 ha, dan tinggi seluas 27.216,72 ha. Berdasarkan penilaian kerentanan sekolah terhadap banjir menunjukkan bahwa terdapat 8 sekolah tidak rentan, 22 sekolah dengan tingkat kerentanan rendah, 16 sekolah kerentanan sedang, dan 4 sekolah kerentanan tinggi. Berdasarkan analisis risiko sekolah terhadap banjir yaitu risiko rendah 10 sekolah, risiko sedang 27 sekolah, dan risiko tinggi 13 sekolah. Hasil analsisi teridentifikasi adanya konsisten antara area tertinggi tingkat kerentanan dan risiko yaitu area Jakarta Utara dan Barat.

Kata kunci: Bahaya, Kerentanan, Analisis Risiko Banjir, Sekolah

\section{PENDAHULUAN}

Provinsi DKI Jakarta merupakan Ibu Kota negara, dengan fungsi sebagai pusat pertumbuhan ekonomi dan bisnis, pusat pemerintahan, dan pusat pendidikan. Kondisi tersebut mengakibatkan DKI Jakarta memiliki daya tarik tinggi untuk masyarakat sebagai area urbanisasi, yang mengakibatkan semakin padatnya jumlah penduduk di Ibu Kota Dahlia, Nurharosono, \& Rosyidin (2018, hlm 81). Akan tetapi, Provinsi DKI Jakarta merupakan salah satu provinsi di Indonesia yang memiliki kerawanan terhadap multi bencana, seperti banjir, longsor, penurunan daratan, cuaca ekstrem, bencana non alam, dan lain-lain (BPDB, 2017). Berdasarkan kondisi demografis dan geografis tersebut wilayah DKI Jakarta berpotensi memiliki tingginya tingkat risiko kerugian baik bagi pemerintah ataupun masyarakat jika terjadi bencana. Bencana banjir merupakan tipe bencana hidrometerologi dengan frekuensi tertinggi terjadi di DKI Jakarta. Menurut BNPB (2018), DKI Jakarta terdapat 463 titik sebaran banjir Jakarta. 149 titik merupakan di Jakarta Barat, 79 titik Jakarta Utara, 68 titik Jakarta Pusat, 35 titik Jakarta Selatan, dan 132 titik Jakarta Timur.

Elemen berisiko pada suatu area rawan bencana bervariasi, seperti: manusia, lingkungan, fasilitas, harta benda, pekerjan, dan lain-lain. Sekolah merupakan salah satu fasilitas kritis dibidang pendidikan yang berpotensi terdampak bencana, terdampaknya sekolah $\begin{array}{lrr}\text { oleh suatu } & \text { bencana } & \text { berpotensi } \\ \text { mengakibatkan } & \text { risiko } & \text { kerugian } \\ \text { terhambatnya } & \text { proses } & \text { pembelajaran. }\end{array}$ Menurut Kemendikbud (2017), terdapat 497.576 sekolah di Indonesia yang terletak di daerah rawan bencana, dan 214 sekolah di DKI Jakarta merupakan rawan terjadap bencana banjir. BNPB (2018), mencatat bahwa kejadian banjir yang terjadi 21 Februari 2017 mengakibatkan 304 sekolah di Provinsi DKI Jakarta terdampak banjir mulai dari jenjang pendidikan TK hingga SMA.

Tingginya potensi risiko DKI Jakarta terhadap bencana mengakibatkan pentingnya upaya penanggulangan bencana. Paradigma penanggulangan bencana sekarang ini lebih menitikberatkan pada upaya penanggulangan risiko bencana, dan tidak bersifat responsive. Penanggulangan risiko bencana dapat dilakukan pada saat sebelum terjadi bencana, dengan melakukan mitigasi bencana baik secara structural ataupun non structural. Mitigasi bencana banjir merupakan upaya yang terbaik dalam penurunan tingkat risiko banjir Heidari (2009, hlm 62). Mitigasi bencana banjir secara structural dapat dilakukan dengan cara pembentukan infrastruktur air seperti drainase Marfai (2011, hlm 46), sedangkan mitigasi non structural dapat dilakukan dengan cara analisis risiko.

Analisis risiko banjir merupakan analaisis yang terdiri dari pemetaan bahaya banjir (Flood Hazard), penilaian 
kerentanan (Vulnarebility Assessment), dan analisis risiko (Risk Analysis) Kellens et al (2013, hlm 4). Bahaya banjir adalah probabilitas terjadinya peristiwa banjir yang berpotensi merusak, pada besaran (magnitude) dan di daerah tertentu dalam jangka waktu tertentu Dang, Babel, \& Luong (2011, hlm 175). Kerentanan adalah derajat potensi kerugian atau kerusakan terhadap elemen yang berisiko yang merupakan akibat dari terjadinya fenomena alam, tingkat kerentanan dan kerusakan elemen berisiko diberi nilai 0 jika tidak ada kerusakan dan nilai 1 jika kerusakan total (UNDRO dalam Thywissen 2006).

Metode untuk mengukur tingkat kerentanan terhadap perubahan iklim yaitu metode ekonometrik dan metode indikator. Metode ekonometrik yaitu digunakan untuk survei data tingkat sosial-ekonomi rumah tangga untuk analisis tingkat kerentanan berdasarkan perbedaan kelompok sosial, sedangkan metode indikator yaitu mengukur tingkat kerentanan berdasarkan memilih beberapa indikator dari seluruh rangkaian indikator yang potensial, yang selanjutnya digabungkan indikator yang terpilih untuk menunjukkan tingkat kerentanan total. Menghitung tingkat kerentanan menggunakan pendekatan indikator dapat dilakukan dengan dua cara yaitu: pertama mengasumsikan bahwa semua indikator mempunyai peran yang sama, sehingga memberi bobot yang sama Cutter, Mitchell, \& Scott (2012, hlm 728).
Memberikan bobot yang berbeda untuk menghindari ketidakpastian bobot yang sama Deressa, Hassan, \& Ringler, (2008, hlm. 5). Menurut Hizbaron Dyah R., Rahmat Panji Nur, Agustina, \& Ngainul (2015, hlm 18) pembobotan bermanfaat untuk menempatkan setiap variabel sesuai dengan kontribusinya terhadap pencapaian tujuan, yaitu mengevaluasi kerentanan.

Penggunaan Geography Information System (GIS) dalam peta risiko banjir merupakan penting, karena tidak hanya menghasilkan tingkat kerawanan area tergenang tetapi dapat mengestimasikan tingkat kerugian property Sinha, Bapalu, Singh, \& Rath (2008. hlm 342). Penelitian ini akan mengfokuskan untuk mengkaji terkait 1). Bagaimanakah distribusi spasial tingkat kerawanan banjir di DKI Jakarta; 2). Bagaimanakah tingkat kerentanan Sekolah Menengah Atas terhadap banjir di DKI Jakarta; 3). Bagaimanakah tingkat risiko banjir Sekolah Menengah Atas di DKI Jakarta.

\section{METODE PENELITIAN}

A. Lokasi dan waktu Penelitian

Penelitian analisis risiko pada elemen berisiko sekolah dilakukan di wilayah Provinsi DKI Jakarta, dengan luas 661,52 $\mathrm{km}^{2}$. Secara astronomis wilayah penelitian terletak diantara $10622^{\prime} 42^{\prime}$ ' $-106^{\circ} 58^{\prime} 188^{\prime}$ ' BT, dan 6²2' 00' - 622'45 LS (Gambar 1).Waktu penelitian akan dilaksanakan pada Bulan Februari Tahun 2020, yaitu pada musim penghujan sesuai dengan kajian penelitian yaitu terkait banjir. 


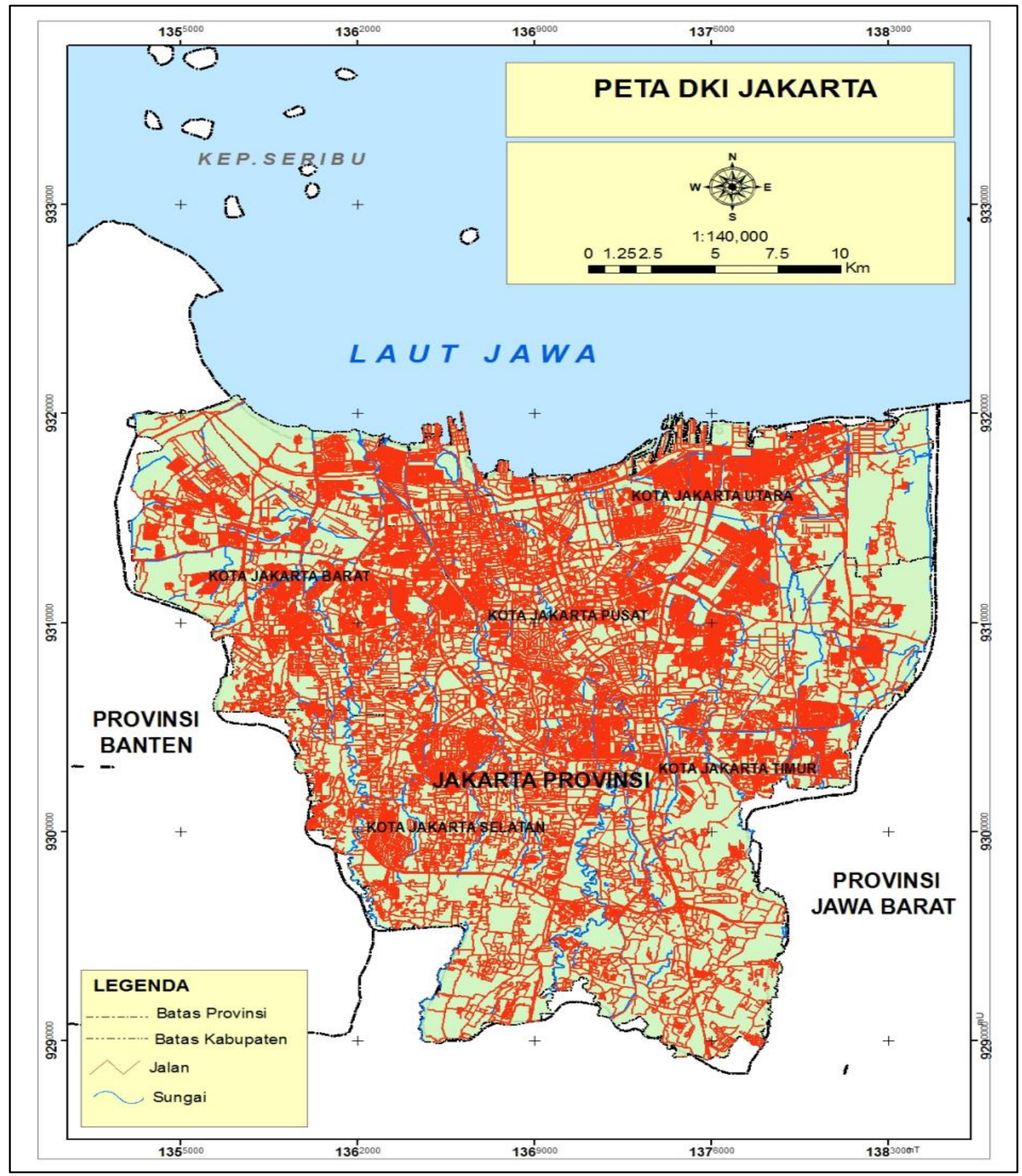

Gambar 1. Lokasi Penelitian

B. Populasi dan Sampel Penelitian

Populasi dalam penelitian ini yaitu Seluruh Sekolah Menengah Atas di DKI Jakarta yang berjumlah 582 sekolah (Tabel 1). Teknik pengambilan sampel yang digunakan yaitu area sampling, yaitu teknik pengambilan sampel dilakukan berdasarkan daerah populasi yang ditetapkan (Sugiyono, 2011). Metode area sampling digunakan dalam penelitian, karena sampel dipilih berdasarkan setiap unit Kota di DKI Jakarta yaitu Jakarta Utara, Barat, Selatan, Timur, dan Pusat.

Tabel 1. Data Sekolah Menegah Atas di DKI Jakarta

\begin{tabular}{rlccc}
\hline No & \multicolumn{1}{c}{ Wilayah } & Negeri & Swasta & Jumlah \\
\hline $\mathbf{1}$ & Kota Jakarta Timur & 40 & 83 & 199 \\
$\mathbf{2}$ & Kota Jakarta Barat & 17 & 101 & 119 \\
$\mathbf{3}$ & Kota Jakarta Selatan & 29 & 75 & 129
\end{tabular}


4 Kota Jakarta Utara

5 Kota Jakarta Pusat

6 Kab. Kepulauan Seribu

Total
17

13

1

117
72

43

0

374
76

58

1

582

(Sumber: https://dapo.dikdasmen.kemdikbud.go.id)

C. Metode Pengumpulan Data

Metode pengumpulan data terdiri dari data primer dan data sekunder. Data primer yang dikumpulan dalam penelitian ini disajikan pada Tabel 2, dan data sekunder Tabel 3:

Tabel 2. Data Primer dan Sumbernya

\begin{tabular}{|c|c|c|}
\hline No & Data & Metode \\
\hline 1 & $\begin{array}{l}\text { Data Historis Banjir (Kedalaman, } \\
\text { luasan, durasi) }\end{array}$ & Wawancara \\
\hline 2 & Kondisi Geografis Sekolah & Observasi dan dokumentasi \\
\hline 3 & Dampak banjir & Wawancara dan observasi \\
\hline 4 & Ploting lokasi sekolah & GPS \\
\hline
\end{tabular}

Tabel 3. Data Sekunder dan Sumbernya

\begin{tabular}{clc}
\hline No & \multicolumn{1}{c}{ Data } & Sumber \\
\hline 1 & Peta RBI skala 1:25.000 & BIG \\
2 & Citra Googel Earth & Googel Earth \\
3 & Data Sekolah & Kemendikbud \\
4 & Data DEM & BIG \\
\hline
\end{tabular}

D. Metode pengolahan dan analisis data

1. Pengolahan dan Analisis untuk peta kerawanan banjir

Pengolahan data Peta RBI, Citra

Googel Earth, DEM menggunakan analisis penskoran dan analisis spasial dengan teknik overlay, untuk menghasilkan peta kerawanan banjir. Peta di representasikan menjadi tiga kelas yaitu kerawanan tinggi dengan warna merah, sedang dengan warna kuning, dan rendah warna hijau.

2. Pengolahan dan Analisis untuk peta kerentanan banjir

Pengolahan dan penilaian tingkat kerentanan sekolah terhadap banjir yaitu: data karakteristik sekolah dianalisis menggunakan metode skoring dengan skala $0-1$, skala 0 tingkat kerentanan minimum dan 1 tingkat kerentanan maksimum. Parameter yang digunakan untuk analsisi tingkat kerentanan yaitu: jarak dari sungai, historis kejadian banjir, bangunan sekolah, dan system evakuasi darurat banjir (Tabel 4). Untuk menghasilkan peta kerentanan menggunakan analisis spasial, sehingga menghasilkan peta kerentanan tinggi, sedang, rendah, dan tidak rentan.

Tabel 4. Indikator Kerentanan

\begin{tabular}{ccccc}
\hline No & Indikator & Kriteria & Bobot & Skor \\
\hline 1 & Jarak dari Sungai & $<0.5 \mathrm{~km}$ & 0.30 & 1 \\
& & $1 \mathrm{~km}$ & & 0.5 \\
& & $>1 \mathrm{~km}$ & 0.30 & 0 \\
2 & Sekolah pernah & Iy & 0.30 &
\end{tabular}




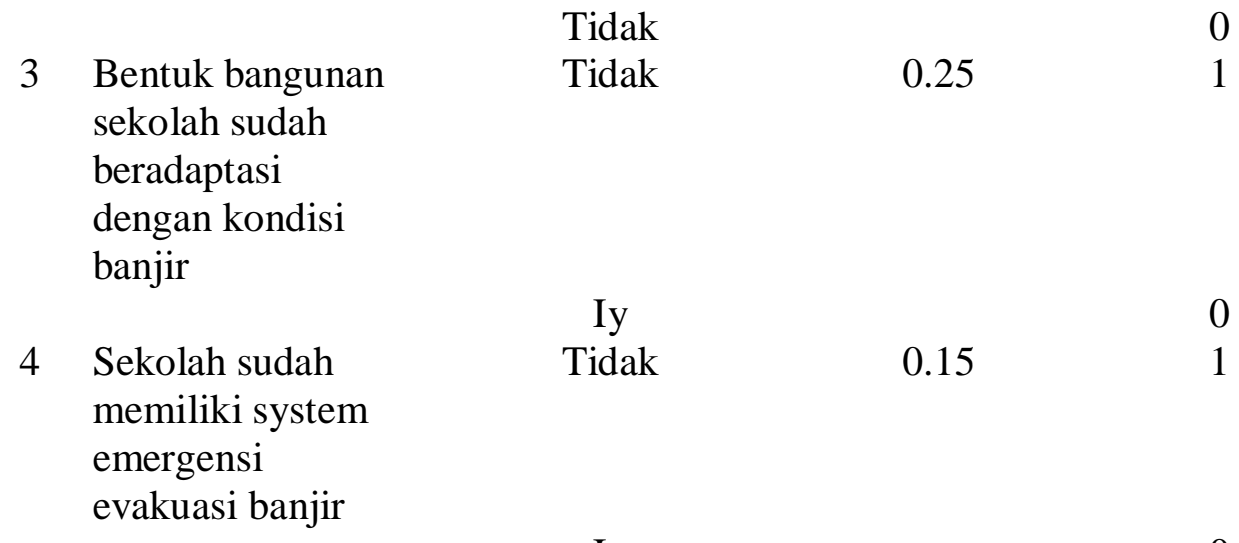

3. Pengolahan dan Analisis untuk peta risiko banjir

Pada penelitian ini analisis risiko berdasarkan matriks risiko yang berdasarkan analisis bahaya dan kerentanan (Tabel 5). Matriks risiko dalam menentukan kategori tigkat risiko berdasarkan kriteria 1) tingkat bahaya rendah dengan tingkat kerentanan rendah maka tingkat risiko rendah, 2) tingkat bahaya sedang dengan tingkat kerentanan rendah maka tingkat risiko rendah, 3) tingkat bahaya tinggi dengan tingkat kerentanan rendah maka tingkat risiko sedang, 4) tingkat bahaya rendah dengan tingkat kerentanan sedang maka tingkat risiko rendah, 5) tingkat bahaya sedang dengan tingkat kerentanan sedang maka tingkat risiko sedang, 6) tingkat bahaya tinggi dengan tingkat kerentanan sedang maka tingkat risiko tinggi, 7) tingkat bahaya rendah dengan tingkat kerentanan tinggi maka tingkat risiko sedang, 8) tingkat bahaya sedang dengan tingkat kerentanan tinggi maka tingkat risiko tinggi, 9) tingkat bahaya tinggi dengan tingkat kerentanan tinggi maka tingkat risiko tinggi.

Tabel 5. Matriks Risiko Banjir Wilayah Penelitian

\begin{tabular}{|l|l|l|l|l|}
\hline \multirow{3}{*}{ Kerentanan } & Tinggi & Sedang & Tinggi & Tinggi \\
\cline { 2 - 6 } & Sedang & Rendah & Sedang & Tinggi \\
\cline { 2 - 5 } & Rendah & Rendah & Rendah & Sedang \\
\hline & & Rendah & Sedang & Tinggi \\
\hline & \multicolumn{4}{|c}{ Bahaya } \\
\hline
\end{tabular}

\section{HASIL DAN PEMBAHASAN}

A. Peta Titik Sampel Sekolah

Pada penelitian ini diambil sebagai

titik sampel yaitu 50 sekolah. Distribusi spasial sekolah-sekolah yang dijadikan titik sampel disajikan pada Gambar 2. 


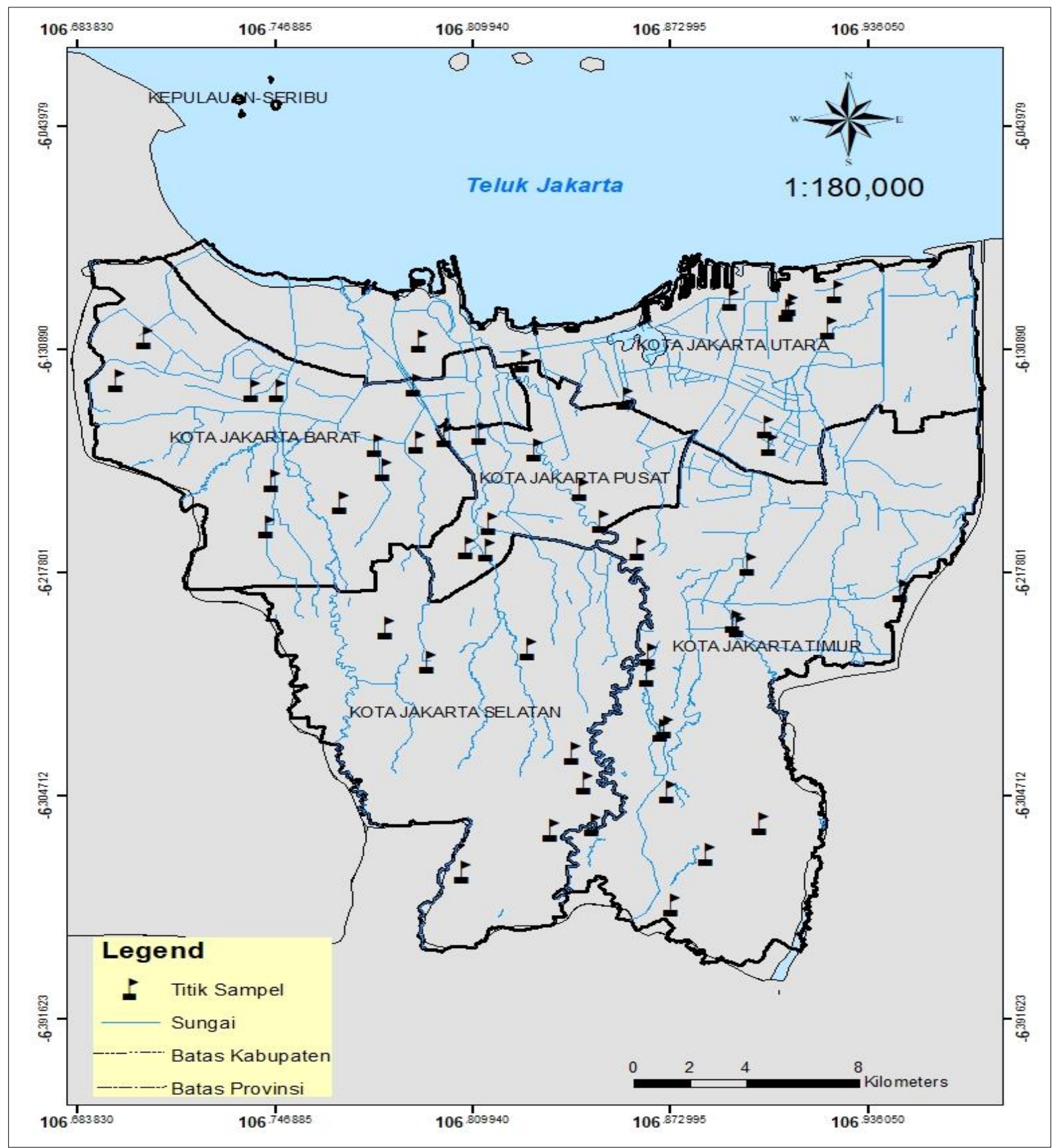

Gambar 2. Peta Titik Sampel Penelitian

B. Peta Kerawanan Banjir Wilayah Penelitian

Hasil analisis kerawanan banjir berdasarkan pendekatan geomorfologi menghasilkan bahwa tingkat kerawanan banjir dengan kategori rendah seluas $13.613,40$ ha, sedang seluas $23.238,67$ ha, dan tinggi seluas 27.216,72 ha. Mayoritas wilayah penelitian memiliki kategori kerawanan tinggi. Area dengan tingkat kerawanan tinggi (warna merah) berada di Utara Jakarta, area dengan tingkat sedang mayoritas di sebagian Jakarta Selatan, Timur, dan Pusat (warna kuning), dan area dengan tingkat kerawanan rendah mayoritas sebagian Jakarta Timur dan Selatan (warna hijau) (Gambar 3). 


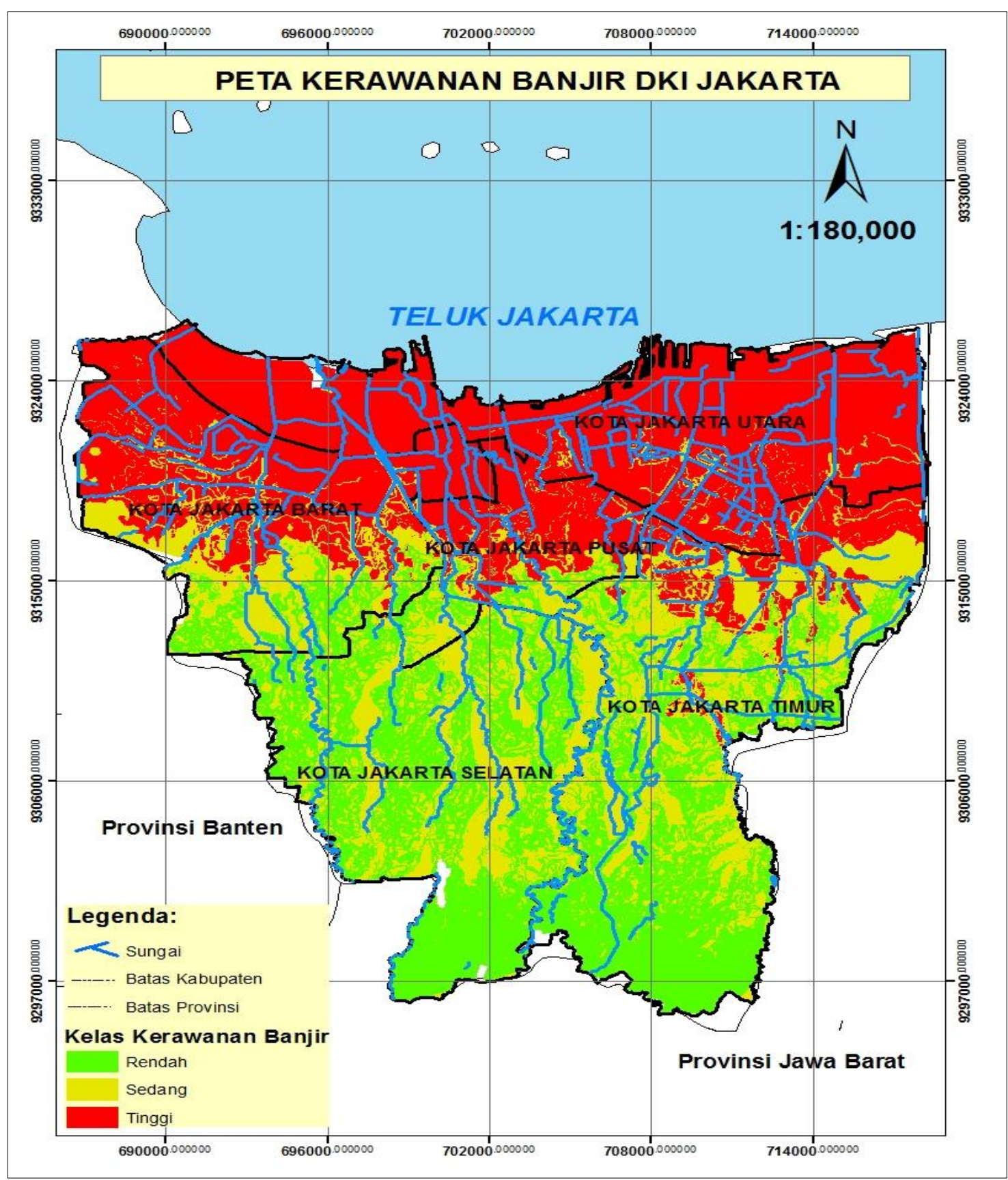

Sumber: (Dahlia et al., 2018)

Gambar 3. Peta Kerawanan Banjir Wilayah Penelitian

Wilayah Jakarta mayoritas merupakan area dengan tingkat kerawanan banjir tinggi, kondisi ini dapat di identifikasi pengaruh kondisi morfologi wilayah penelitian yang merupakan area cekungan banjir dan secara geomorfologi merupakan area datan banjir. Selain itu, Jakarta Utara merupakan zona merah terhadap banjir karena Jakarta dilalui oleh 13 sungai yang bermuara di Teluk Jakarta. Menurut Putri, dkk., (2016, hlm 41), dari
13 sungai tersebut Sungai Ciliwung memiliki kontribusi besar terhadap banjir di DKI Jakarta. Selain itu, area utara Jakarta merupakan area yang mengalami penurunan dataran, sehingga menambah potensi dampak banjir dari luapan sungai dan pasang surut air laut.

\section{Kerentanan}

Pada penilaian tingkat kerentanan terhadap elemen berisiko yaitu sekolah 
terhadap bahaya banjir. Indikatorindikator yang digunakan untuk analisis kerentanan yaitu jarak dari sungai, historis kejadian banjir, bentuk bangunan sekolah, dan system manajemen bencana banjir yang sudah di implementasikan di sekolah. Berdasarkan penilaian kerentanan menghasilkan terdapat 8 sekolah tidak rentan, 22 sekolah dengan tingkat kerentanan rendah, 16 sekolah kerentanan sedang, dan 4 sekolah kerentanan tinggi (Tabel 6). Berdasarkan hal tersebut menunjukkan bahwa mayoritas Sekolah Menengah Atas di Jakarta memiliki kerentanan rendah terhadap bahaya banjir. Kondisi ini di dasarkan atas bangunan sekolah yang sudah beradaptasi dengan kondisi banjir, seperti dibangun dengan 2 atau 3 lantai dan peninggian pondasi bangunan. Adanya sekolah yang tidak rentan terhadap banjir, kondisi tersebut di sebabkan lokasi sekolah yang jauh dari sungai.

Tabel 6. Hasil Tingkat Kerentanan

\begin{tabular}{llc}
\hline No & Kelas & Jumlah Sekolah \\
\hline 1 & Tidak Rentan & 8 \\
2 & Kerentanan Rendah & 22 \\
3 & Kerentanan Sedang & 16 \\
4 & Kerentanan Tinggi & 4 \\
& Jumlah & 50 \\
\hline
\end{tabular}

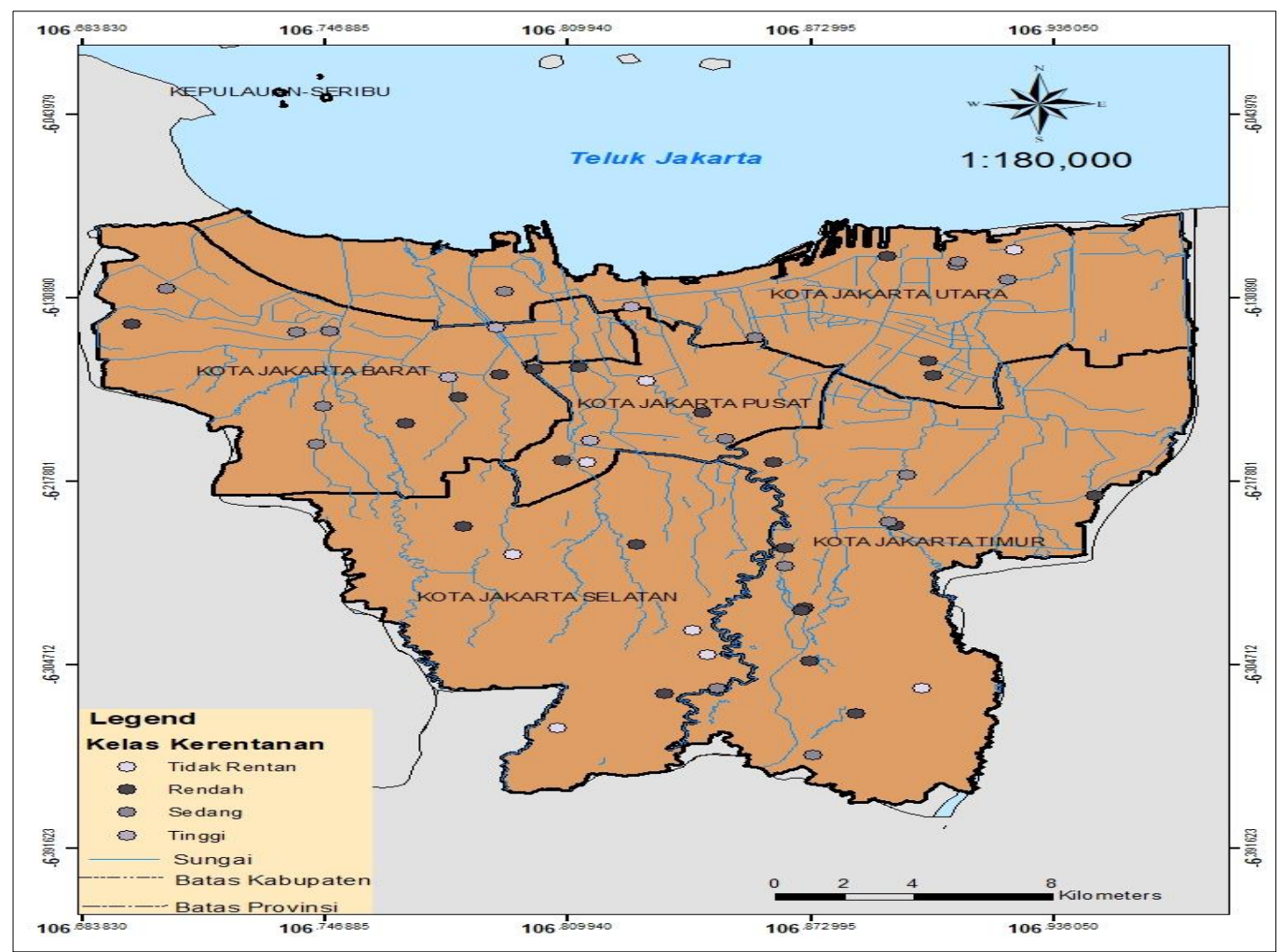

Gambar 4. Peta Kerentanan Sekolah Menengah Atas di DKI Jakarta

Peta tingkat kerentanan Sekolah Menengah Atas di wilayah penelitian disajikan pada Gambar 4. Secara spasial menunjukkan bahwa tingkat kerentanan tertinggi sekolah terdapat di wilayah Jakarta Barat dan Jakarta Utara. Kondisi tersebut dapat di identifikasi pengaruh lokasi geografis sekolah yang dilalui 
sungai bagian hilir yang akan bermuara ke Teluk Jakarta, sehingga sekolah pada wilayah Jakarta Barat dan Utara lebih rentan terhadap bahaya banjir.

\section{Analisis Risiko Banjir Terhadap Sekolah}

Analisis risiko banjir yaitu mengetahui risiko banjir pada masa lalu, sekarang atau yang akan datang, berdasarkan penentuan tingkat bahaya, kerentanan dan risiko banjir (Schanze, 2006). Pada penelitian ini analisis risiko berdasarkan matriks risiko yang berdasarkan analisis bahaya dan kerentanan (Tabel 5). Hasil analisis risiko wilayah penelitian berdasarkan bahaya
(Gambar 3) dan kerentanan (Gambar 4) menggunakan matriks risiko (Tabel 5) menghasilkan kelas tingkat risiko sekolah yaitu risiko rendah 10 sekolah, risiko sedang 27 sekolah, dan risiko tinggi 13 sekolah (Tabel 7). Beradaskan hal tersebut, hal ini menjukkan bahwa mayoritas Sekolah Menengah Atas di wilayah penelitian memiliki risiko terhadap bahaya banjir sedang. Hal ini dapat di identifikasi factor kondisi morfologi wilayah penelitian yang merupakan dataran rendah, muara atau hilir sungai, dilalui beberpa aliran sungan dan merupakan area pemukiman padat. Kondisi tersebut secara tidak langsung berdampak pada tingginya risiko banjir wilayah penelitian.

Tabel 7. Hasil Tingkat Risiko Sekolah Terhadap Bahaya Banjir

\begin{tabular}{ccc}
\hline No & Kelas & Jumlah Sekolah \\
\hline 1 & Rendah & 10 \\
2 & Sedang & 27 \\
3 & Tinggi & 13 \\
& Jumlah & 50 \\
\hline
\end{tabular}

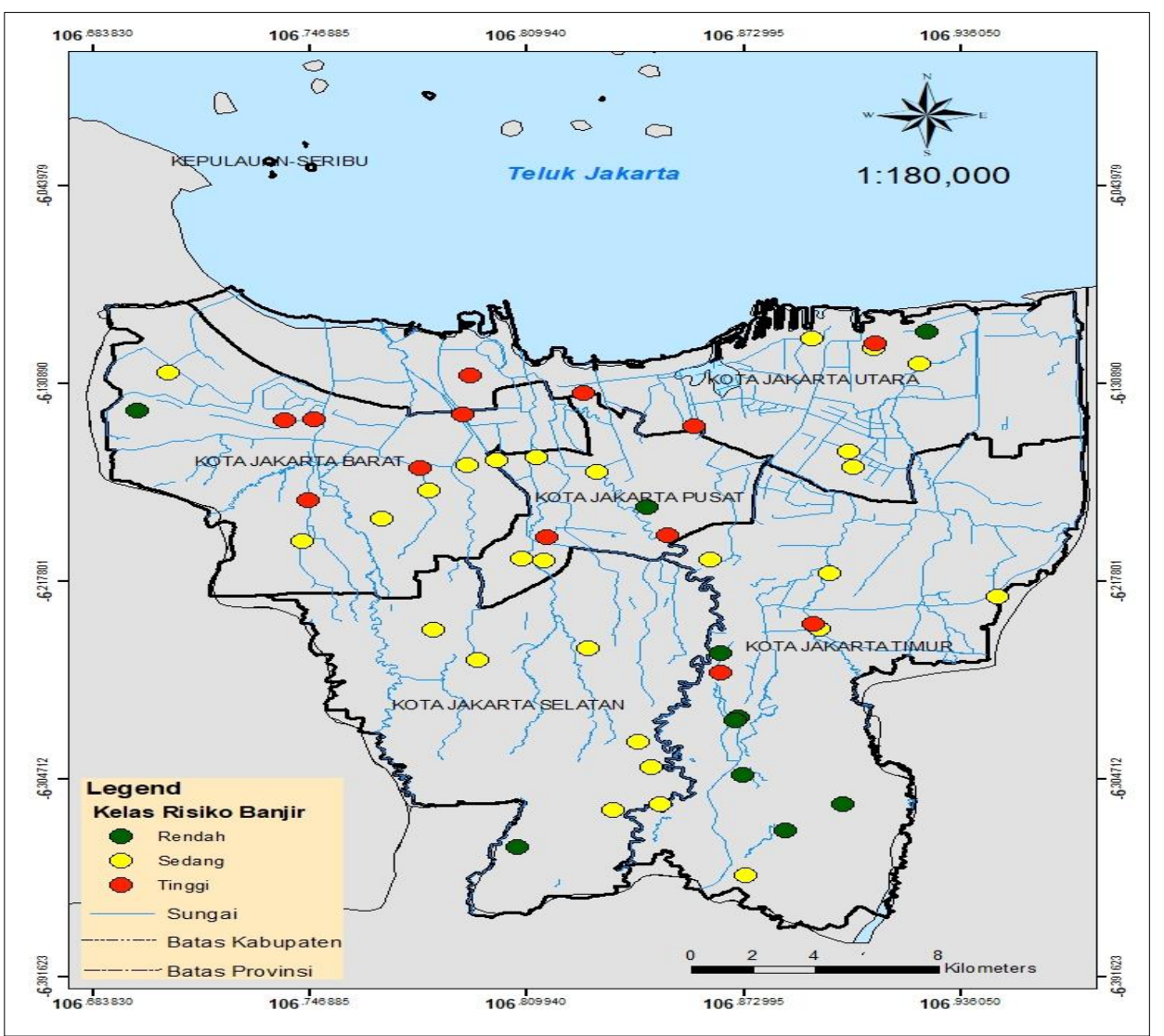

Gambar 5. Peta Risiko Banjir Wilayah Penelitian 
Peta risiko banjir terhadap sekolah di wilayah penelitian di sajikan pada Gambar 5. Hasil menunjukkan bahwa sekolah dengan risiko banjir tertinggi terdapat di wilayah Jakarta Utara, Barat, Jakarta Pusat, dan Jakarta Timur. Akan tetapi, tingkat risiko tinggi sampai sedang mayoritas terdapat di Jakarta Utara dan Barat. Hal ini konsisten dengan tingkat kerentanan yang menujukkan area Jakarta Utara dan Barat merupakan area yang terbanyak memiliki sekolah dengan tingkat risiko dan kerentanna tinggi. Hal ini dapat di dientifikasi lokasi geografis wilayah tersebut yaitu area muara sungai.

\section{SIMPULAN}

Hasil daerah dengan tingkat kerawanan banjir rendah seluas 13.613,40 ha, sedang seluas $23.238,67$ ha, dan tinggi seluas 27.216,72 ha. Berdasarkan penilaian kerentanan sekolah terhadap bahaya banjir menunjukkan bahwa terdapat 8 sekolah tidak rentan, 22 sekolah dengan tingkat kerentanan rendah, 16 sekolah kerentanan sedang, dan 4 sekolah kerentanan tinggi. Berdasarkan analisis risiko sekolah terhadap banjir yaitu risiko rendah 10 sekolah, risiko sedang 27 sekolah, dan risiko tinggi 13 sekolah. Hasil analsisi teridentifikasi adanya konsisten antara area tertinggi tingkat kerentanan dan risiko yaitu area Jakarta Utara dan Barat.

\section{REKOMENDASI}

Berdasarkan hasil penelitian, untuk itu peneliti menyampaikan beberapa rekomendasi terkait hasil riset:

1. Untuk penelitian selanjutnya, keterbatasan penelitian dalam melaksanakan penelitian untuk itu peneliti terbatas hanya pada analisis risiko Sekolah Menengah Atas terhadap banjir. Untuk itu, peneliti selanjutnya dapat mengkaji elemen berisiko lainnya, dan kondisi manajemen bencana yang di implementasikan di sekolah

2. Untuk pemangku kebijakan, hasil penelitian dapat dijadikan sebagai referensi dalam penentu kebijakan terkait penanggulangan bencana banjir di DKI Jakarta.

\section{DAFTAR PUSTAKA}

Cutter, S. L., Mitchell, J. T., \& Scott, M. S. (2012). Revealing the vulnerability of people and places: A case study of Georgetown county, South carolina. Hazards, Vulnerability and Environmental Justice, 90(4), 83114. https://doi.org/10.4324/97818497715 42.

Dahlia, S., Nurharosono, T., \& Rosyidin, W. F. (2018). Analisis Kerawanan Dan Exposure Banjir Menggunakan Citra Dem Srtm Dan Landsat Di Dki Jakarta. Jurnal Pendidikan Geografi, 18(1), 81-95.

Dang, N. M., Babel, M. S., \& Luong, H. T. (2011). Evaluation of food risk parameters in the Day River Flood Diversion Area, Red River Delta, Vietnam. Natural Hazards, 56(1), 169-194. https://doi.org/10.1007/s11069-0109558-x.

Deressa, T., Hassan, R. M., \& Ringler, C. (2008). Measuring Ethiopian farmers' vulnerability to climate change across regional states. IFPRI Discussion Paper, 806(October), 32. Retrieved from http://www.ifpri.org/publication/meas uring-ethiopian-farmersvulnerability-climate-change-acrossregional-

states\%5Cnhttp://www.ifpri.org/sites/ default/files/publications/ifpridp0080 6.pdf.

Heidari, A. (2009). Structural master plan of flood mitigation measures. Natural Hazards and Earth System Science, 9(1), 61-75. https://doi.org/10.5194/nhess-9-61- 
2009.

Hizbaron Dyah R., Rahmat Panji Nur, Agustina, S., \& Ngainul, M. M. (2015). Kajian Pola Spasial Kerentanan Sosial, Ekonomi, dan Fisik di Wilayah Rawan Erupsi Gunungapi Merapi. Jurnal Riset Kebencanaan Indonesia, 1(1), 16-24. Retrieved from ttp://www.iabiindonesia.org/wpcontent/uploads/2015/07/JRKI-Vol1No1-2015-compressed-4.pdf.

Kellens, W., Vanneuville, W., Verfaillie, E., Meire, E., Deckers, P., \& De Maeyer, P. (2013). Flood Risk Management in Flanders: Past Developments and Future Challenges. Water Resources Management, 27(10), 3585-3606. https://doi.org/10.1007/s11269-0130366-4.

Putri, M. A., Rahayu, M. J., \& Putri, R. A. (2016). Bentuk Morfologi Kawasan Permukiman Urban Fringe Selatan Kota Surakarta. Jurnal
Pengembangan Kota, 4(2), 120. https://doi.org/10.14710/jpk.4.2.120128.

Sinha, R., Bapalu, G. V., Singh, L. K., \& Rath, B. (2008). Flood risk analysis in the Kosi river basin, north Bihar using multi-parametric approach of Analytical Hierarchy Process (AHP). Journal of the Indian Society of Remote Sensing, 36(4), 335-349. https://doi.org/10.1007/s12524-0080034-y.

BNPB. (2018). Data Bencana Indonesia 2017. Jakarta: Pusat Data, Informasi dan Humas Badan Nasional Penanggulangan Bencana.

Data Pokok Pendidikan Dasar dan Menengah Direktorat Jenderal Pendidikan Anak Usia Dini, Pendidikan Dasar dan Pendidikan Menengah Kementerian Pendidikan dan Kebudayaan https://dapo.dikdasmen.kemdikbud.go .id/ 